\title{
Microstructure Characterization of Ni-Based Alloys for Packaging Application upon Long-Term Heat Treatment
}

\author{
Jianbing Ren ${ }^{1}$, Yilong $\mathrm{Ma}^{2}$ and Kejian $\mathrm{Li}^{2, *}$ \\ 1 School of Mechanical and Power Engineering, Chongqing University of Science \& Technology, \\ Chongqing 401331, China; 1995021@cqust.edu.cn \\ 2 School of Metallurgy and Materials Engineering, Chongqing University of Science \& Technology, \\ Chongqing 401331, China; yilongma@163.com \\ * Correspondence: 2017004@cqust.edu.cn; Tel.: +86-23-65023701
}

check for updates

Citation: Ren, J.; Ma, Y.; Li, K. Microstructure Characterization of Ni-Based Alloys for Packaging Application upon Long-Term Heat Treatment. Coatings 2021, 11, 1159. https://doi.org/10.3390/ coatings11101159

Academic Editor: Shih-Chen Shi

Received: 31 August 2021

Accepted: 24 September 2021

Published: 26 September 2021

Publisher's Note: MDPI stays neutral with regard to jurisdictional claims in published maps and institutional affiliations.

Copyright: (c) 2021 by the authors. Licensee MDPI, Basel, Switzerland. This article is an open access article distributed under the terms and conditions of the Creative Commons Attribution (CC BY) license (https:// creativecommons.org/licenses/by/ $4.0 /)$.
Featured Application: The developed materials are specific applied to the field of medical thermal packaging.

\begin{abstract}
In this study, an investigation was conducted to examine two types of Ni-based alloys upon long-term heat treatment and compare their grains, surface corrosion layers and microhardness values. The working environment of the tested samples was a temperature of $1000{ }^{\circ} \mathrm{C}$ for $5000 \mathrm{~h}$. Two samples, respectively, contained low ( $~ 8 \mathrm{wt} . \%)$ and high ( 16 wt.\%) contents of Mo, and the low-Mo-content sample contained $\mathrm{Nb}(\sim 4 \mathrm{wt} . \%)$ and other elements. The grains, precipitates, corrosion layers and microhardness values of the samples before and after heat treatment were determined by scanning electron microscopy, electron back-scattered diffraction, transmission electron microscopy, X-ray diffraction analysis and Vickers hardness tests. The results revealed that the grain was surprisingly stable in the sample with the higher Mo content; after heat treatment, the grain size was $\sim 35 \mu \mathrm{m}$, which was similar to the grain size before heat treatment. Moreover, for the sample with the higher Mo content, the microhardness was found to be higher, especially after long-term high-temperature treatment, which is of great significance for the long service life of materials.
\end{abstract}

Keywords: Ni alloy; Mo addition; grain size; precipitate; heat treatment

\section{Introduction}

Ni-based alloys have attracted increasing attention as new candidates for hightemperature materials due to their high hardness, low density, good corrosion resistance and good dimensional stability [1]. The addition of molybdenum (Mo) to Ni-based alloys is of great importance due to its wide range of applications, especially under long-term high-temperature heat treatment [2]. Among the different alloys containing molybdenum, Ni-Mo alloys are of great interest due to their high corrosion resistance and low overpotential for hydrogen evolution reaction [3]. The content of Mo in Ni-based alloys is closely related to the grain size, lattice defect structure and hardness [4]. Moreover, the effects of the addition of niobium $(\mathrm{Nb})$ on the microstructures of $\mathrm{Ni}$-based alloys were systematically investigated by Wei et al. [5]. In an $\mathrm{Ni}$-based alloy with the addition of $\mathrm{Nb}$, needle-like Mo-rich MC carbides and granular $\mathrm{Nb}$-containing $\mathrm{M} 2 \mathrm{C}$ carbides were found to form in the matrix and at the grain boundaries, respectively. Based on the interface energy analyses, the morphological differences between the $\mathrm{MC}$ and $\mathrm{NbC}$ carbides were found to result from their different orientation relationships and interface structures.

The present work was to investigate the effects of two kinds of Ni-based alloys. First one with the addition of $\sim 8 \mathrm{wt} . \% \mathrm{Mo}$, and $\sim 4 \mathrm{wt} . \% \mathrm{Nb}$. The second specimen was $\sim 16 \mathrm{wt} . \%$ Mo without $\mathrm{Nb}$ contained. They are tested under long-term heat treatment in the field of medical thermal packaging. 


\section{Materials and Methods}

The tested specimens were heating plates taken from a packaging production line, as displayed in Figure 1. The working environment of the tested samples was a temperature of $1000{ }^{\circ} \mathrm{C}$ for 7 months (approximately $5000 \mathrm{~h}$ ). Four samples from the working area and the original area were, respectively, marked as samples \#1-4. The grain size was measured by scanning electron microscopy (SEM, JSM-7800F, Tokyo, Japan) and electron back-scatter diffraction (EBSD), which were performed by a field emission scanning electron microscope (FESEM) (a JSM-7800F system installed with an oxford scan mode and a beam step size of $300 \mathrm{~nm}$, Oxford, UK). The acceleration voltage of SEM image mode was at $5 \mathrm{kV}$, working distance was $10 \mathrm{~mm}$, magnification ranges from $\times 100$ to $\times 1000$, scale bar was attached to each image, and resolution of image was $640 \times 480$ pixels. The precipitated phase was analyzed by transmission electron microscopy (TEM, JEOL 2100F, Tokyo, Japan) operated at $200 \mathrm{kV}$. For the TEM sample preparation, the tested specimens were first mechanically polished to $100 \mu \mathrm{m}$ in thickness, after which they were polished by a Struers TenuPol5 electrolytic polishing device at room temperature with an electrolyte solution of $10 \%$ perchloric acid and 90\% acetic acid. For the phase analysis, X-ray diffraction (XRD) analyses of the surface layers were conducted using a X-ray (Rigaku Smart Lab-9, Tokyo, Japan) diffractometer with $\mathrm{Cu} \mathrm{K} \alpha$ radiation.

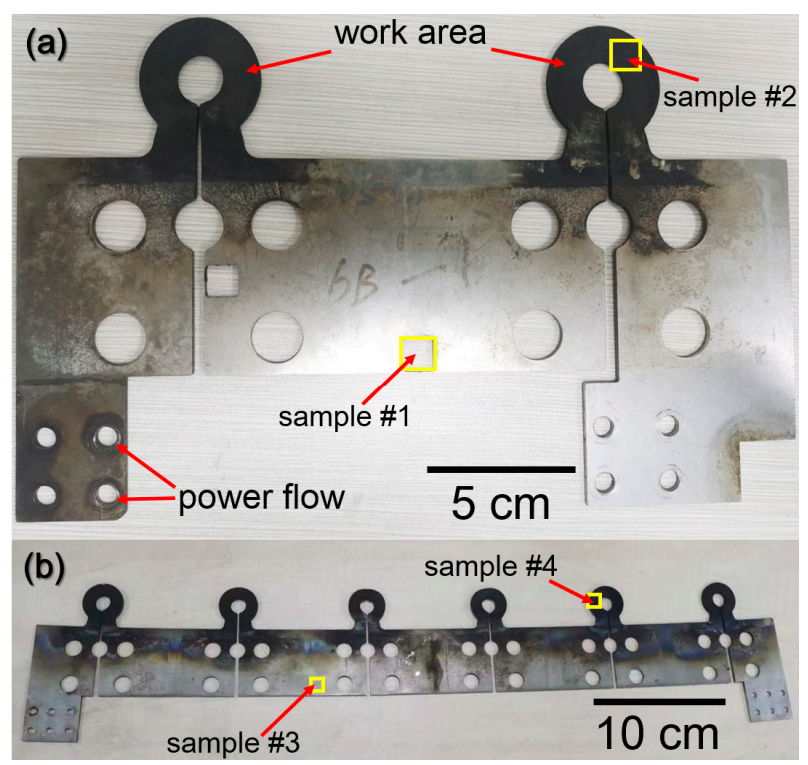

Figure 1. Photos of medical thermal packaging heater band after long-term heat treatment (a) sample $\# 1$ and \#2; (b) sample \#3 and \#4.

\section{Results}

The main chemical compositions of the tested materials are reported in Table 1. Specimens \#1 and \#3 were the matrixes, and specimens \#2 and \#4 were the surfaces of after heat treatment, respectively. Figure 2 presents the SEM characterization of the specimens before and after heat treatment; based on the comparison of Figure $2 a, b$, it is evident that the grains grew obviously after heat treatment. The grains in sample \#1 were homogeneous and had twin structures, and the grain size of sample \#2 was around $100 \mu \mathrm{m}$. However, as shown in Figure 2c,d, there was no obvious change in grain size between specimens \#3 and $\# 4$, except that many precipitates were found at the grain boundary (GB). To determine why the grains of sample \#3 did not grow up after high-temperature heat treatment, the microstructures of samples \#2 and \#4 were analyzed in detail. Figure 3 presents the results of SEM/EDS mapping, which reveal that the surface enrichment of Mo and $\mathrm{Nb}$ was obvious after high-temperature heat treatment, and no significant local enrichment of $\mathrm{W}$ and $\mathrm{Ni}$ was found. As shown in Figure 3( $\left.b_{2}\right)$, a large amount of Mo was precipitated at the GB and 
covered almost the whole grain. Grain growth was also obvious from the EBSD analysis, as shown in Figure 4. Therefore, it is speculated that a large amount of $\mathrm{Mo}$ and $\mathrm{Nb}$ will precipitate at the GB in a long-term high-temperature environment, thereby hindering the growth of grains.

Table 1. Chemical composition testing results by EDS of after heat treatment specimens (wt.\%).

\begin{tabular}{|c|c|c|c|c|c|c|c|c|c|c|c|c|c|c|c|c|}
\hline Elem. & C & O & $\mathrm{Na}$ & Al & Si & $\mathrm{Cl}$ & $\mathbf{K}$ & $\mathrm{Ca}$ & $\mathrm{Ti}$ & $\mathrm{Cr}$ & Mn & $\mathrm{Fe}$ & $\mathrm{Ni}$ & $\mathrm{Nb}$ & Mo & $\mathbf{W}$ \\
\hline$\# 1$ & - & - & - & 0.22 & 0.15 & - & - & - & 0.26 & 22.19 & 0.25 & 3.84 & 59.8 & 4.05 & 8.93 & 0.31 \\
\hline \#2 & 7.15 & 12.75 & 0.23 & 0.33 & 0.23 & 0.23 & 0.1 & 0.21 & 0.49 & 32.89 & 0.87 & 4.11 & 33.46 & 4.76 & 1.81 & 0.38 \\
\hline \#3 & - & - & - & - & - & - & - & - & 0.05 & 16.18 & 0.62 & 6.29 & 57.36 & - & 16.15 & 3.35 \\
\hline$\# 4$ & 17.84 & 14.88 & 1.54 & 0.27 & 0.92 & 0.11 & 0.17 & 0.3 & 0.02 & 19.22 & 11.07 & 2.43 & 10.89 & - & 10.12 & 10.22 \\
\hline
\end{tabular}
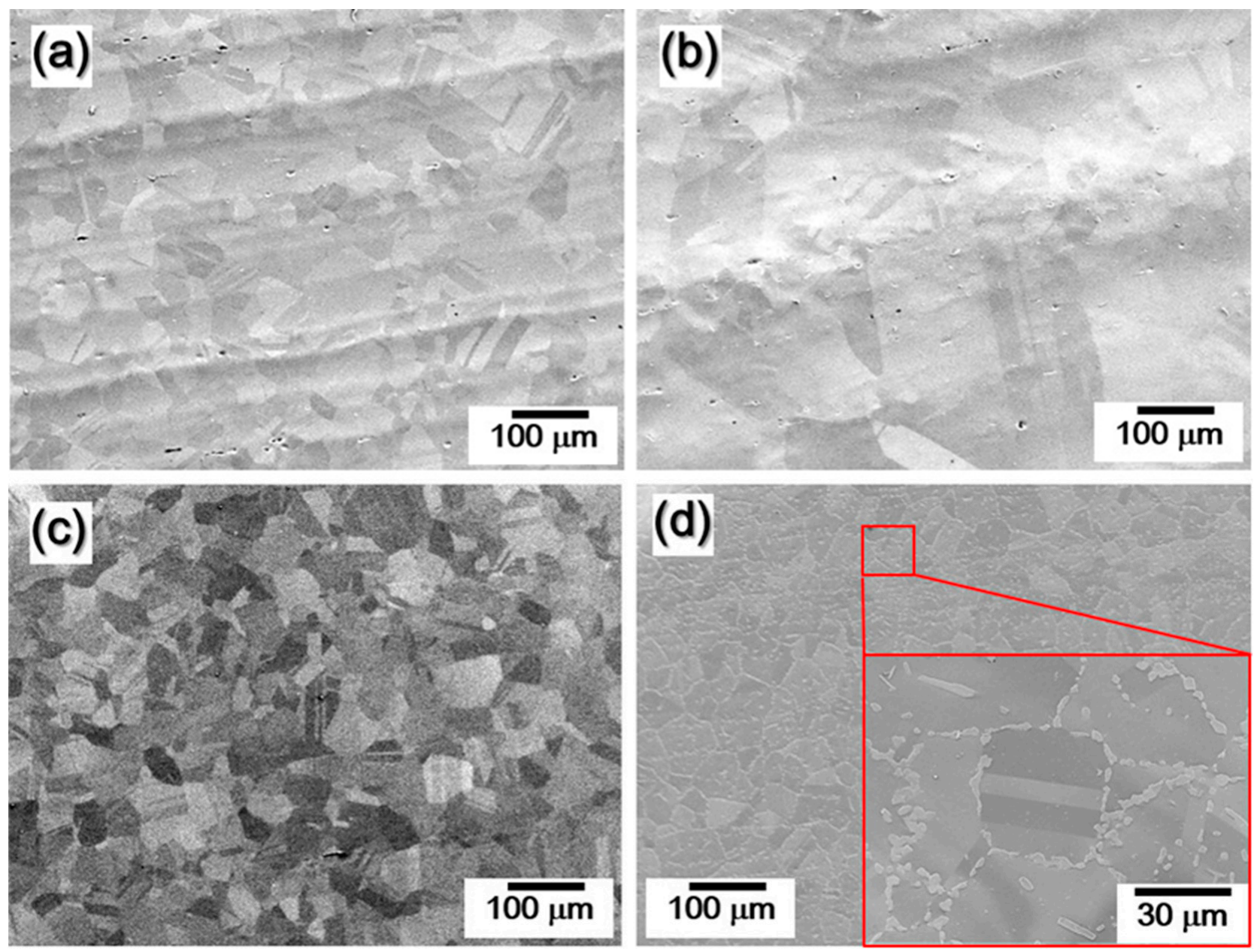

Figure 2. SEM characterization of the Ni-based alloys before and after heat treatment; specimens (a) \#1, (b) \#2, (c) \#3 and (d) \#4. 


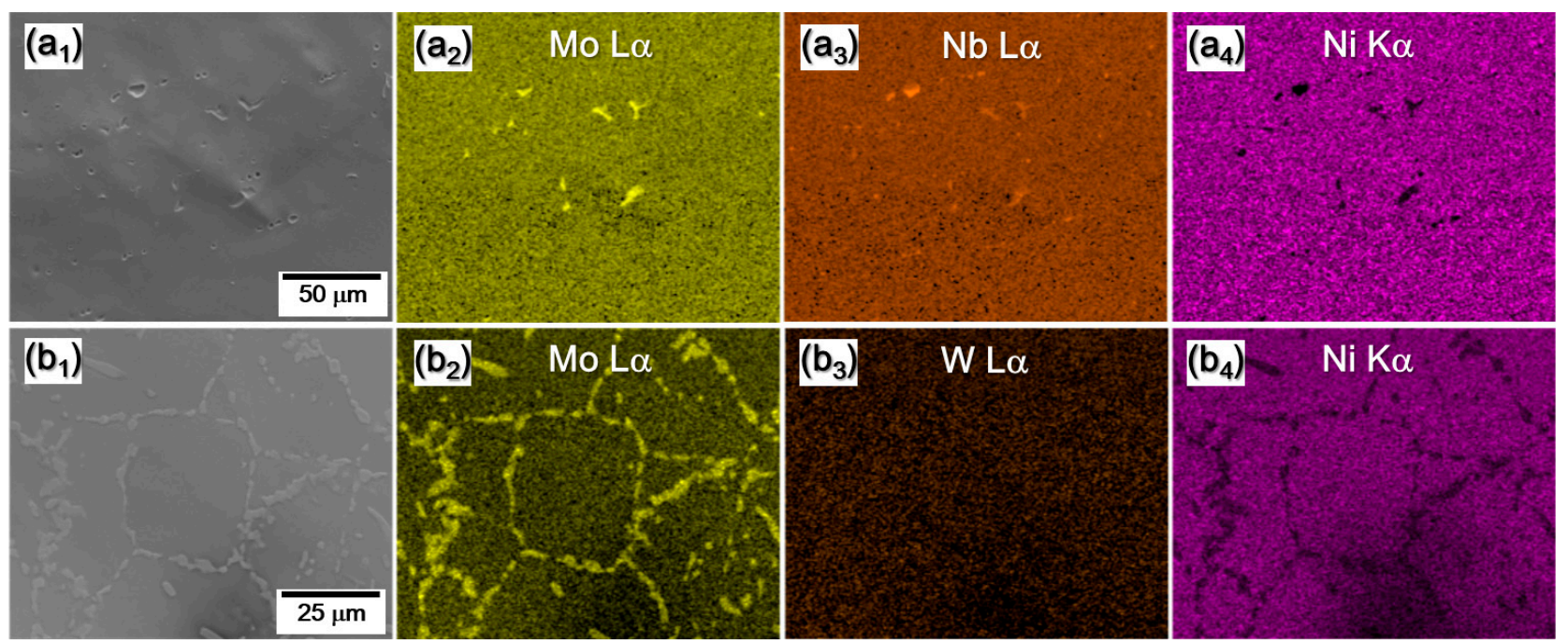

Figure 3. Distributions of the characteristic elements analyzed by SEM and the EDS elemental mapping of specimens ( $\left.\mathbf{a}_{1}-\mathbf{a}_{4}\right)$ $\# 2$ and $\left(\mathbf{b}_{1}-\mathbf{b}_{4}\right) \# 4$.
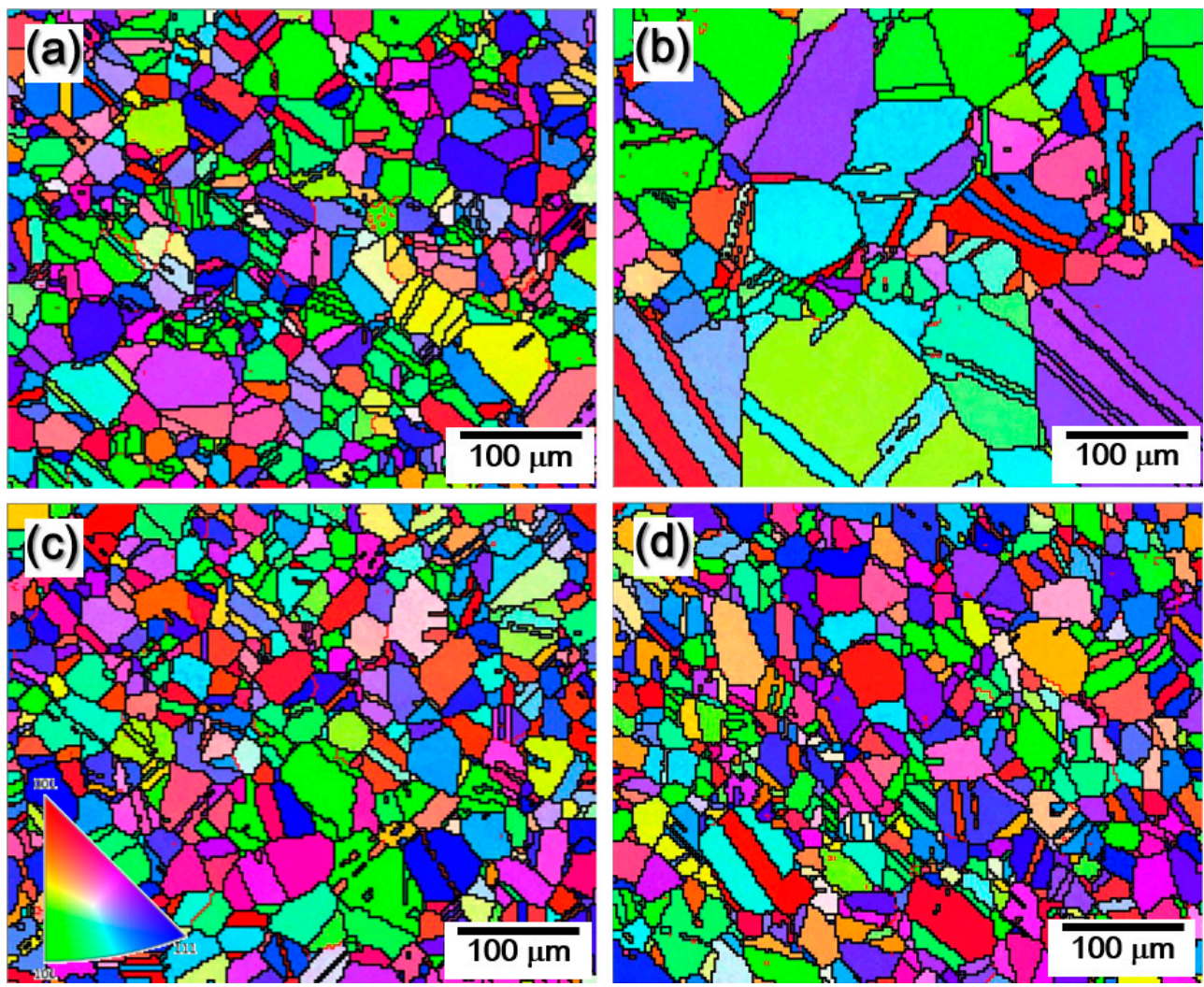

Figure 4. EBSD characterization of the Ni-based alloys before and after heat treatment: specimens (a) \#1, (b) \#2, (c) \#3 and (d) \#4.

Figure 5 presents the TEM analysis, which also confirms the presence of a large number of precipitates near the grain boundaries. Twin structures were identified inside of the precipitated phase. The selected area diffraction pattern (SADP) in Figure $5 \mathrm{f}$ reveals double bright spots, which correspond to the twin structure shown in Figure 5c. Preliminary research has confirmed the distribution of granular and thin rod-like $\mathrm{M}_{2} \mathrm{C}$ carbides in the matrix and at the grain boundaries [5]. However, in this work, most of the precipitates were found to be located at the GB. Figure 6a presents a closer observation of one particle 
as revealed by TEM. In the high magnification image (b), the chemical composition (c) and atomic arrangement spacing of the precipitated phase are proved (d). Based on the results, the precipitates were not only Mo carbides, but also $\mathrm{W}$ carbides. The distances between their atoms were, respectively, 0.44 and $0.48 \mathrm{~nm}$.
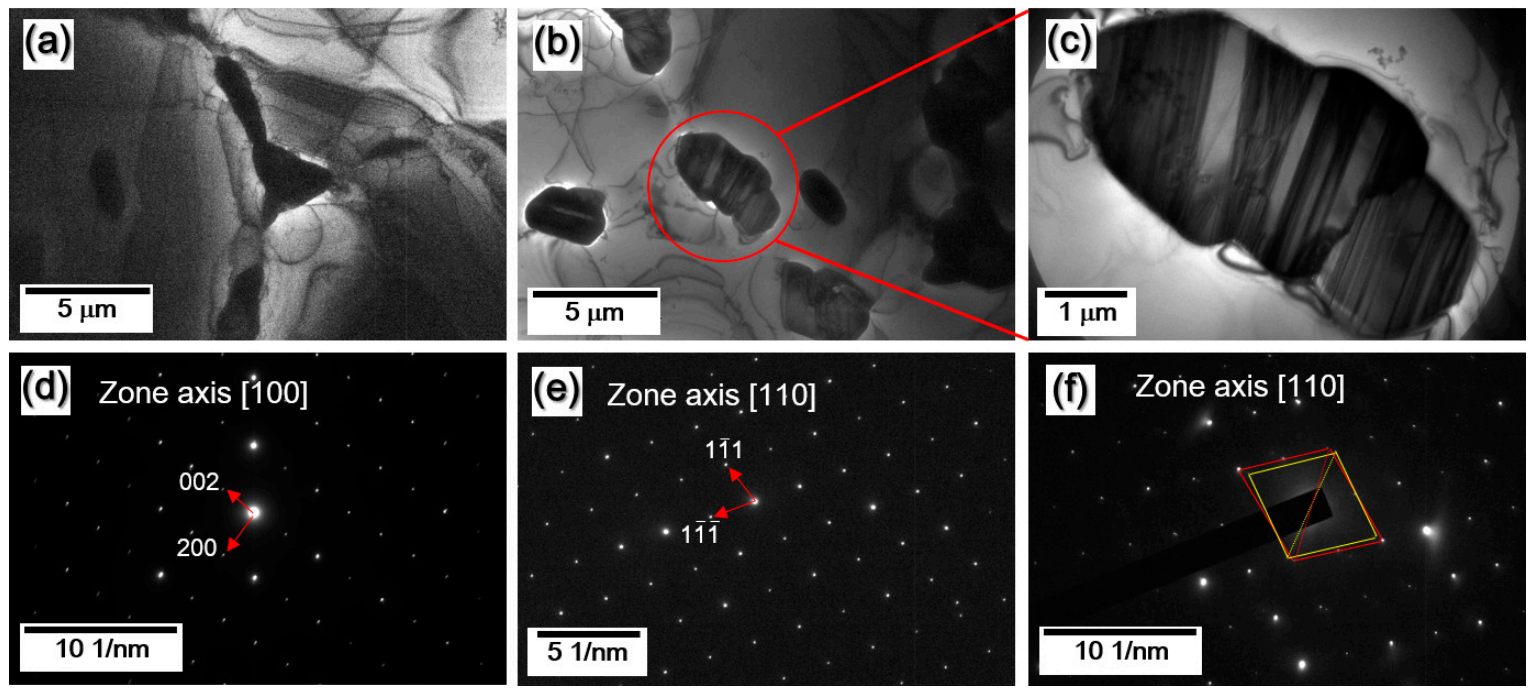

Figure 5. TEM characterization of specimen \#4: $(\mathbf{a}-\mathbf{c})$ the precipitate near the GB, $(\mathbf{d}-\mathbf{f})$ the corresponding SADPs.
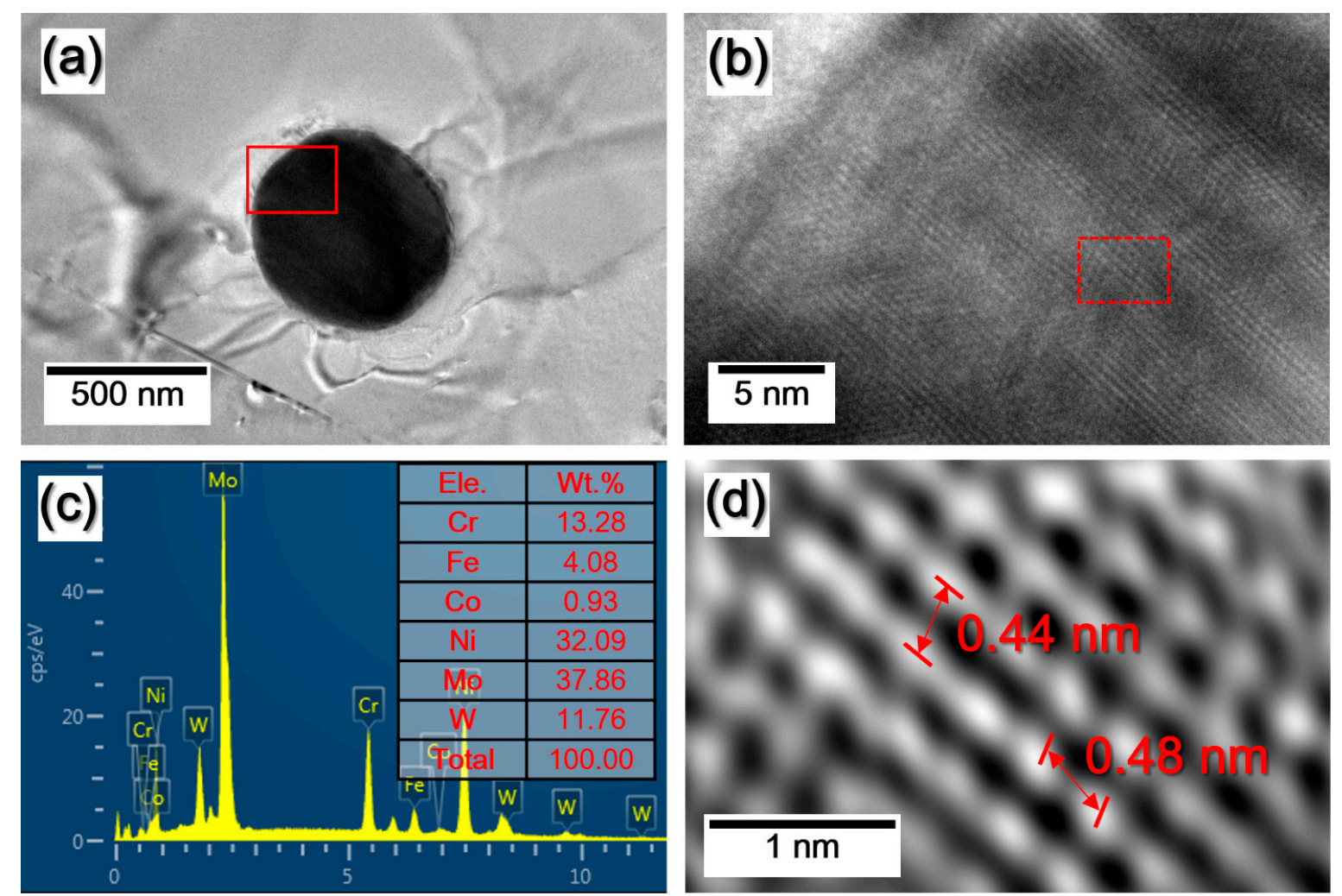

Figure 6. The closer observation of a precipitate particle: (a) TEM image, (b) high-magnification image of the square in (a), (c) EDS analysis of the precipitate, (d) high-resolution image of the square in (b) after inverse Fourier transform.

XRD and SEM were employed to observe and compare the surface phases and corrosion products of the Ni-based alloys before and after working in a high-temperature environment. Figure 7 presents the XRD analysis of the surfaces of the materials. Specimens 
$\# 1$ and \#3 mainly exhibited an Ni matrix phase, while specimens \#2 and \#4 mainly exhibited an oxide phase sintered after high-temperature treatment. The signal peak positions of the matrix are marked in the figure. By comparing the maps of specimens \#2 and \#4, it can be seen that there were significant differences between the products of high-temperature oxidation in the two groups of samples. However, because the composition was very complex, the oxidized surface of the material was not a single oxidized product.
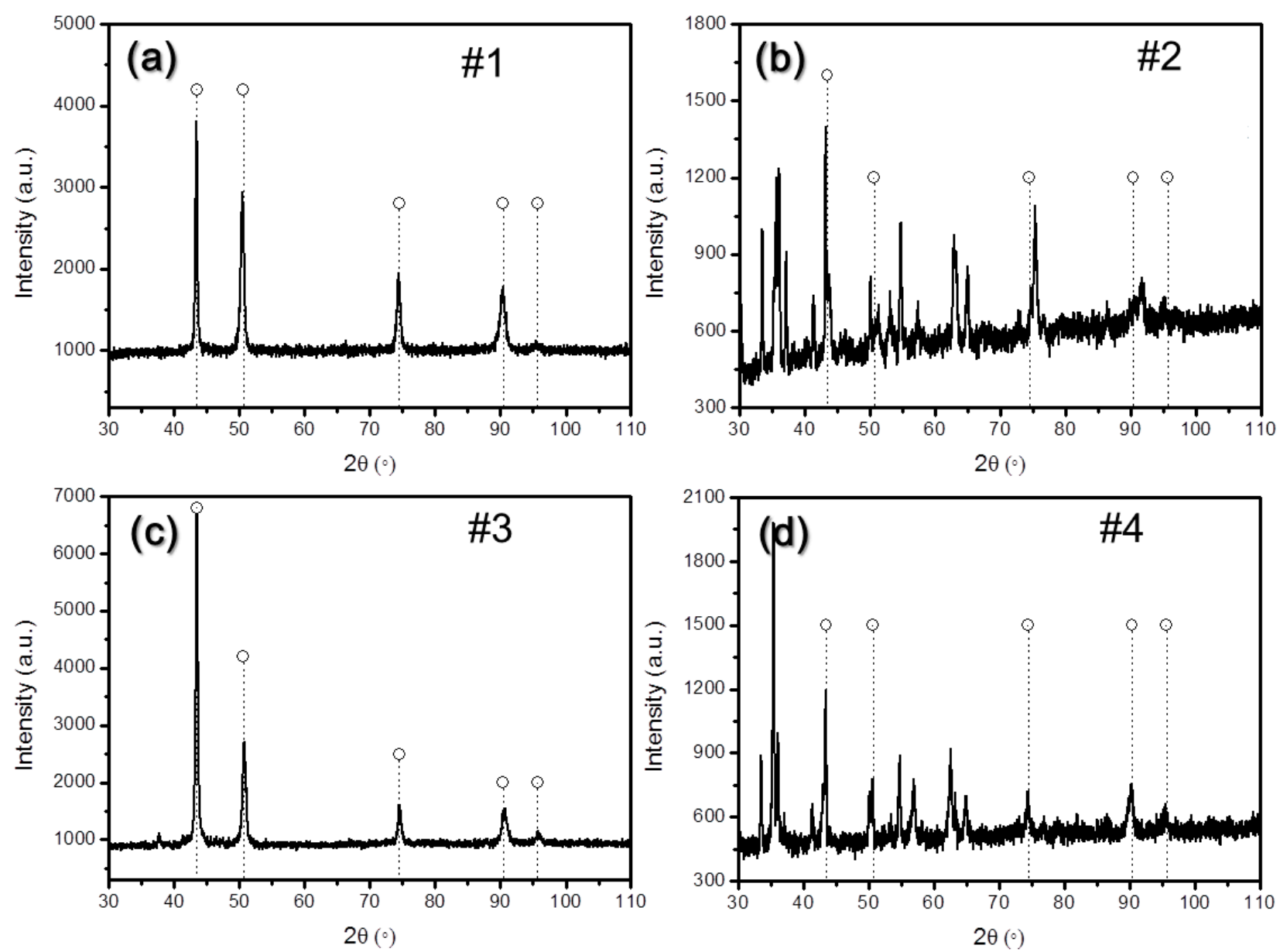

Figure 7. The surface XRD patterns of the Ni-based alloys before and after heat treatment: specimens (a) \#1, (b) \#2, (c) \#3 and (d) \#4.

Figure 8 is SEM images to observe the surfaces of specimens \#2 and \#4, and the comparison of the surface morphologies of the material oxides reveals that the products on the surfaces of the two samples were very continuous and dense. Crystallization of corrosion products were obviousd, and their roughness parameter and surface texture analysis [6] will be shown in future work. EDS surface scanning revealed continuously distributed $\mathrm{Cr}$ and $\mathrm{Nb}$ oxides on the substrate surface (see Figure 9). Particle enrichment was obvious in specimen \#3, and EDS surface scanning proved that the enrichment was mainly of $\mathrm{Cr}$ and $\mathrm{C}$, as well as some granular impurities (see Figure 10). In the research by Ye [7], the influence of $\mathrm{Nb}$ on the oxidation behavior of a novel $\mathrm{Ni}$-based superalloy at $1000{ }^{\circ} \mathrm{C}$ was investigated in detail. Even though the alloy with $2 \mathrm{wt} . \% \mathrm{Nb}(2 \mathrm{Nb})$ exhibited significantly higher weight gain than the alloy without $\mathrm{Nb}(0 \mathrm{Nb})$, the oxide scale of $2 \mathrm{Nb}$ was more continuous and compact. In contrast, $0 \mathrm{Nb}$ underwent severe vaporization and spallation in the oxide scale. $\mathrm{Nb}$ was found to accelerate the formation of compact $\mathrm{TiO}_{2}$ on the $\mathrm{Cr}_{2} \mathrm{O}_{3}$ layer, leading to inhibited vaporization and spallation in the oxide scale. $\mathrm{Nb}$ was also found to accelerate the formation of a continuous $\mathrm{Cr}$ oxide layer, thereby enhancing 
the oxidation resistance via the inhibition of the interdiffusion of oxygen, nitrogen and metallic elements. However, in the present study, $\mathrm{Cr}, \mathrm{Nb}$ and Mo oxides were obvious as the continuous oxide layer in specimen \#2. Most of the elemental enrichment in specimen \#4 was in the form of particles. Therefore, the samples with low and high contents of Mo studied in this work exhibited different corrosion mechanisms.
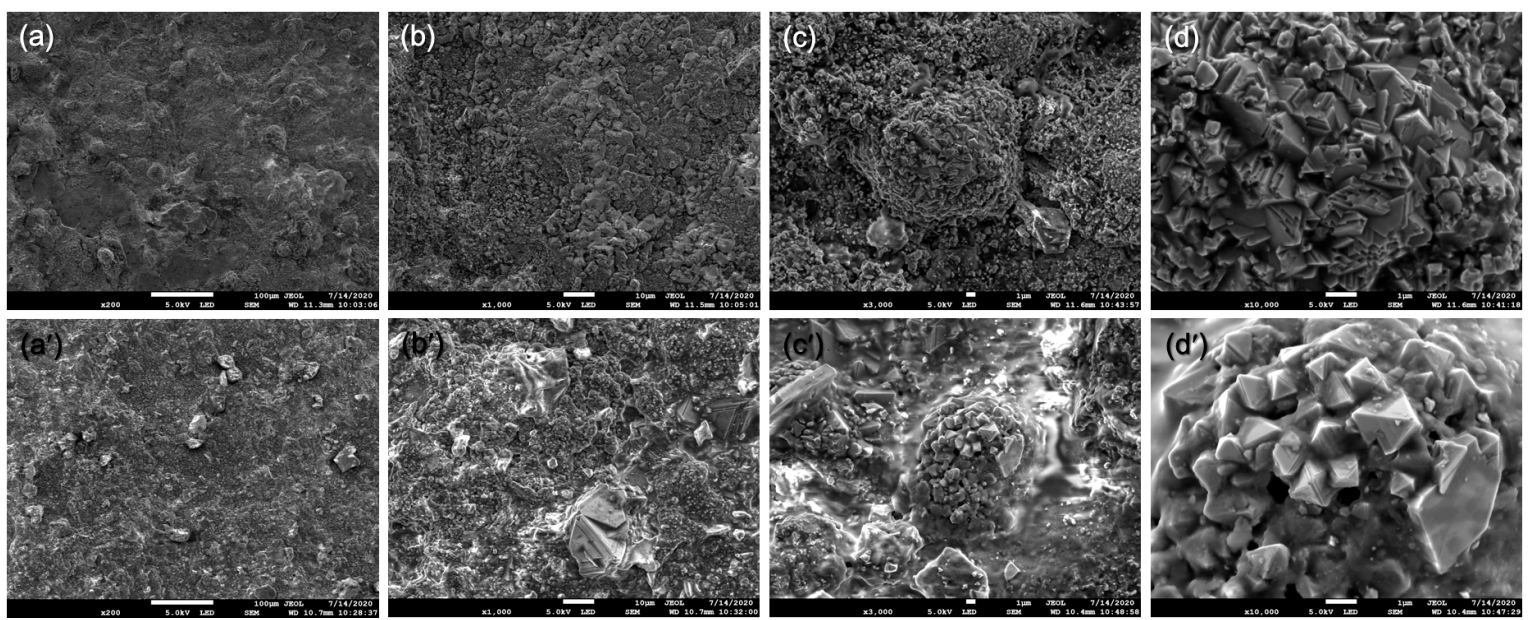

Figure 8. The surface analysis based on SEM: specimens (a-d) \#2 and ( $\left.\mathbf{a}^{\prime}-\mathbf{d}^{\prime}\right) \# 4$.
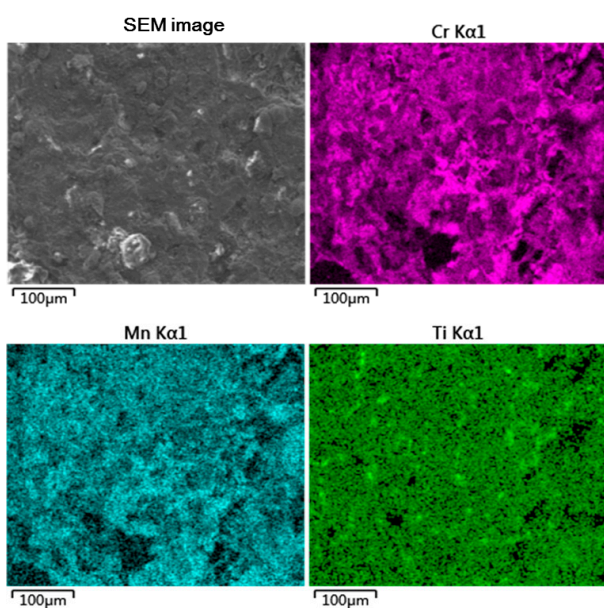

$100 \mu \mathrm{m}$

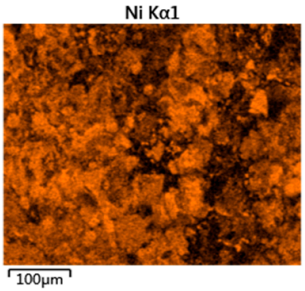

$\mathrm{CK} \alpha 12$

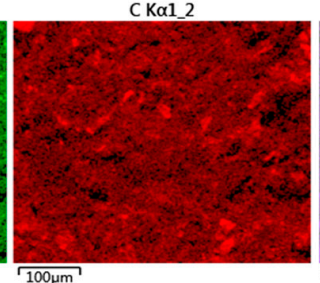

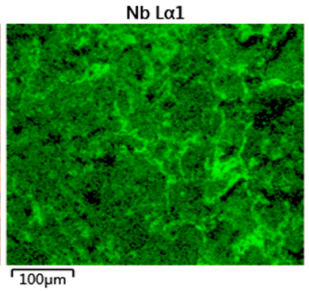

$\mathrm{Cl} \mathrm{K \alpha 1}$

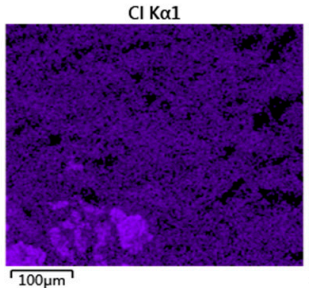

$\sqrt{100 \mu \mathrm{m}}$
Mo 1 al

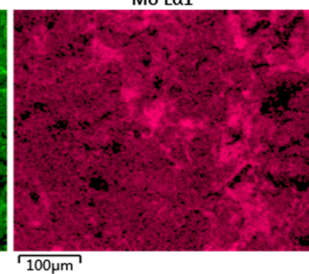

Na K $\alpha 12$

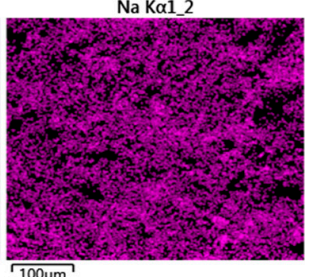

$100 \mu \mathrm{m}$

Figure 9. The surface analysis of sample \#4 based on the EDS mapping.
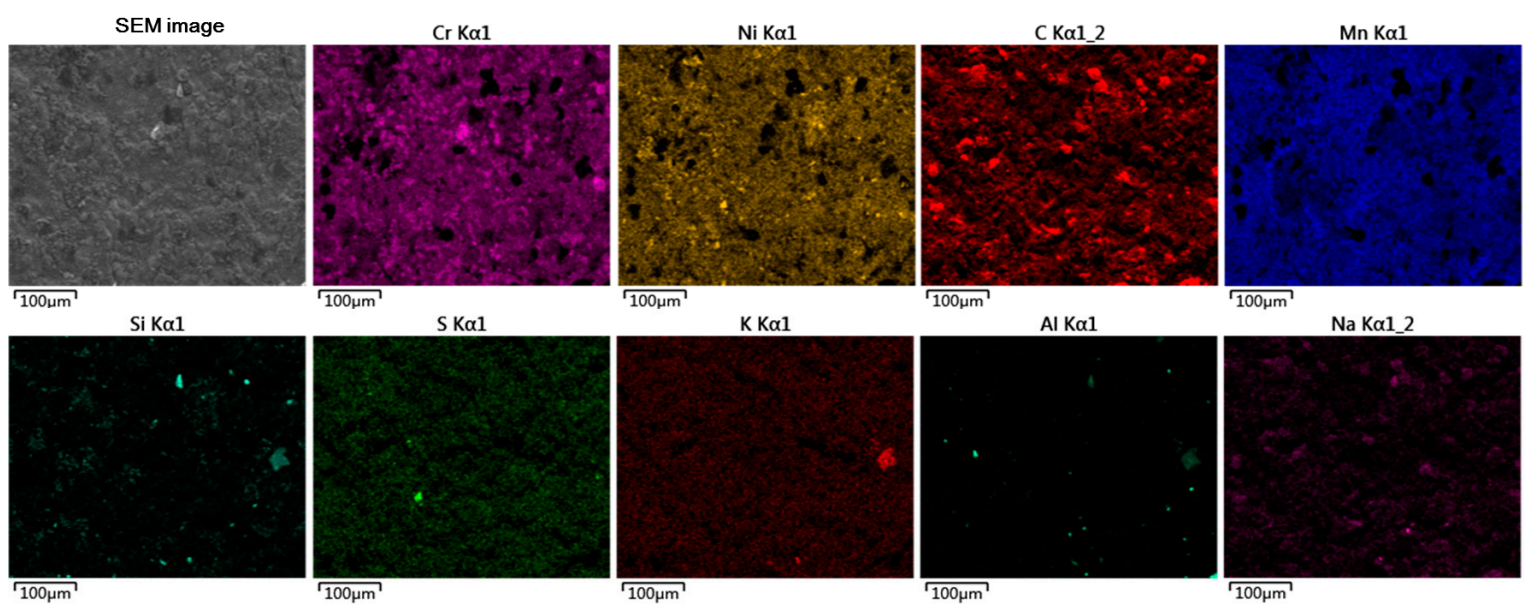

Na Ka1_2

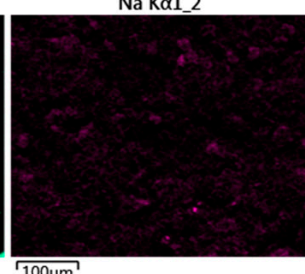

Figure 10. The surface analysis of sample \#4 based on EDS mapping. 
Figure 11 is the result of microhardness measurement. The microhardness test was performed with a load of $200 \mathrm{~g}$ and a loading time of $10 \mathrm{~s}$, taken from matrix of each specimen. all tested specimens were metallographically polished and 5-8 points were selected to calculate the average value. It reveals that the hardness changed greatly from specimen \#1 to specimen \#2, and that the material properties decreased obviously. In contrast, from specimen \#3 to specimen \#4, the hardness remained relatively stable.

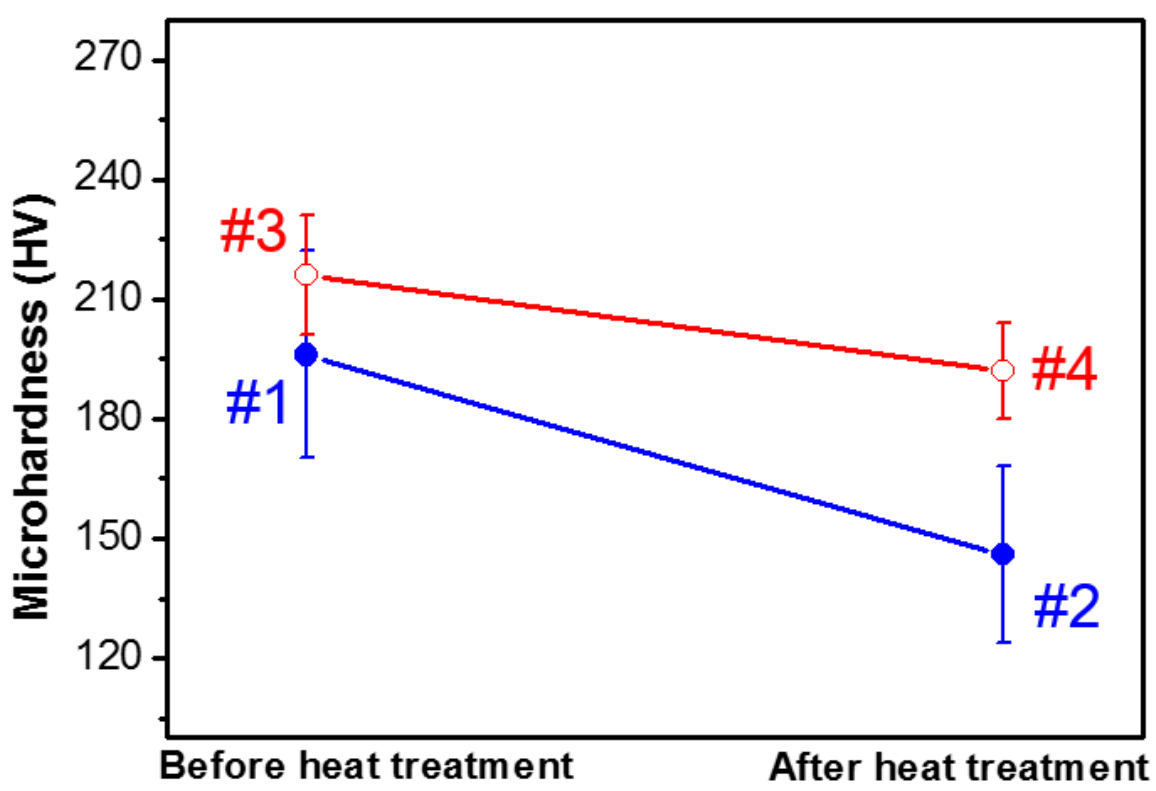

Figure 11. Microhardness of Ni-based alloys before and after heat treatment.

\section{Discussion}

The practical performances of polycrystalline materials are strongly affected by the formed microstructure inside, which is mostly dominated by grain growth behaviors. High temperatures will cause the growth of crystals, which many research institutes find undesirable [8]. The general theory reveals that the switch from abnormal to normal grain growth is caused by GB roughening transition. The behaviors of grain growth dominate the formation of the microstructure inside polycrystalline materials and thus strongly influence their practical performances. However, grain growth behaviors still remain ambiguous. Hu et al. [9] propose a new migration model of GB and further derive a mathematical expression to depict the general evolution of grain growth in the cellular structures. The expression incorporates the variables influencing growth rate (e.g., GB features, grain size and local grain size distribution) and thus reveals how the normal, abnormal and stagnant behaviors of grain growth occur in polycrystalline systems. In polycrystalline materials, grain growth occurs at elevated temperatures to reduce the total area of grain boundaries with high energy. The grain growth rate usually slows down with annealing time, making it hard to obtain grains larger than a millimeter in size [10]. Lee et al. [11] discussed an abnormal grain growth and GB faceting in a model Ni-base superalloy, when heat-treated in a solid solution temperature range above the solvus temperature $\left(1150{ }^{\circ} \mathrm{C}\right)$ of the $\gamma^{\prime}$ phase. Kim et al. [12] simulated the GB kinetics in terms of GB segregation of solute atoms for an isolated grain embedded in a matrix and demonstrated that the phase-field simulation could describe the GB movement under conditions of GB segregation in a quantitatively correct way, then they modeled grain growth in association with GB segregation in twodimensional polycrystalline systems, and clarified that similarity between the Cottrell effect and the solute drag effect holds even on the macroscopic scale, that is, abnormal grain growth (AGG) can be induced by the solute drag effect. This AGG can take place spontaneously in homogeneous systems without any texture, anisotropy of GB mobility and/or energy, pinning particles and grain size advantage. 
Superalloy has the fact that its structural changes depend on melting process, alloying elements, working temperatures and attended times. In this study, the main works is characteristic of grain size and Mo concentration after heat treatment. The structures and properties of various materials were compared, and the crystal in specimen \#1 (with a higher Mo content) was very stable, which can maintain good hardness and a long service life. Therefore, theoretical analysis of grain growth is referred to the previous researches, the following conclusions are put forward:

(1) Positioning gaps or obstructions around the crystals is a very effective approach to hinder crystal growth;

(2) Mo and $\mathrm{Nb}$ are beneficial and precipitate readily at grain boundaries;

(3) The addition of a high content of Mo ( $16 \mathrm{wt} . \%)$ is an effective method for restraining the high-temperature grain growth of Ni-based alloys.

Crystals have shapes similar to those found in daily life, such as the stone floor tiles depicted in Figure 12a. While crystals have a tendency to grow at high temperatures, crystal growth is hindered by the constraints of the GB, as shown in Figure 12b. Therefore, the addition of elements such as Mo and $\mathrm{Nb}$ plays an important role in controlling the grain size upon long-term heat treatment.
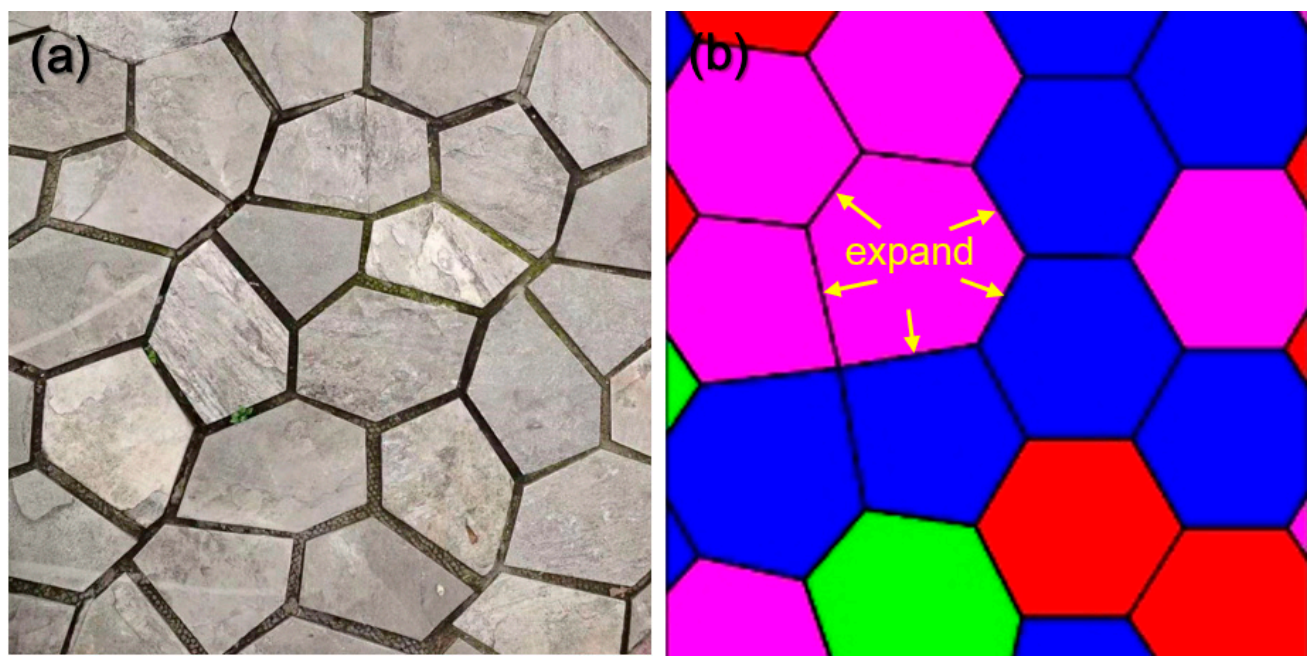

Figure 12. (a) Stone floor tiles, (b) diagram of crystal.

\section{Conclusions}

The addition of Mo to Ni-based alloys can significantly improve the high-temperature properties of the material. In this study, the comparison of samples with low ( 8 wt.\%) and high ( 16 wt.\%) contents of Mo revealed that the Mo in the material is gathered at the grain boundaries at high temperatures, the concentration of molybdenum is obvious. Continuous precipitates are formed, and grain growth is hindered, which is helpful for improving the thermal stability of the material. The surface morphologies of the material oxides reveal that the products on the surfaces of the two samples were very continuous and dense, continuously distributed $\mathrm{Cr}$ and $\mathrm{Nb}$ oxides on the substrate surface. The microhardness value of the sample with a high content of Mo was found to decrease less after high-temperature heat treatment, and the thermal stability was superior.

Author Contributions: Conceptualization, J.R.; methodology, J.R.; formal analysis, K.L.; investigation, Y.M.; resources, K.L.; data curation, K.L.; writing-original draft preparation, review and editing, Y.M.; project administration, K.L. All authors have read and agreed to the published version of the manuscript.

Funding: This research was funded by State Key Laboratory of Vehicle NVH and Safety Technology, Grant No. NVHSKL-202104, China. 
Institutional Review Board Statement: Not applicable.

Informed Consent Statement: Not applicable.

Data Availability Statement: Some or all data, models, or code generated or used during the study are available in a repository or online in accordance with funder data retention policies.

Conflicts of Interest: The authors declare no conflict of interest.

\section{References}

1. Yuan, K.; Wang, Y.; Zheng, L.; Zhang, H. Microstructural evolution, mechanical properties, and oxidation performance of highly Ni-rich NiTi alloys with added V using vacuum arc melting. J. Alloys Compd. 2021, 877, 160263. [CrossRef]

2. Abdel-Karim, J.H.R.; El-Raghy, S.; Nabil, M.; Waheed, A. Surface morphology and electrochemical characterization of electrodeposited Ni-Mo nanocomposites as cathodes for hydrogen evolution. J. Alloys Compd. 2012, 530, 85-90. [CrossRef]

3. Mohamed, A.M.A.; Ahmad, Y.H.; Golden, T.D.; D'Souza, N. Electrodeposition of nanocrystalline Ni-Mo alloys from alkaline glycinate solutions. Int. J. Electrochem. Sci. 2014, 9, 6438-6450.

4. Kapoor, G.; Yi, H.; Subra, V.; Langdon, T.; Gubicz, J. Effect of Mo addition on the microstructure and hardness of ultrafine-grained $\mathrm{Ni}$ alloys processed by a combination of cryorolling and high-pressure torsion. Mater. Sci. Eng. A 2017, 688, 92-100. [CrossRef]

5. Wang, W.; Jiang, L.; Ye, X.-X.; Liu, R.-D.; Li, C.-W.; Liang, J.-P.; Wang, D.J.; Li, Z.-J. Effect of Nb addition on the microstructure of $\mathrm{Ni}-12 \mathrm{Mo}-7 \mathrm{Cr}$ based superalloy. J. Alloys Compd. 2020, 828, 154137. [CrossRef]

6. Țălu, Ș. Micro and Nanoscale Characterization of Three Dimensional Surfaces. Basics and Applications; Napoca Star Publishing House: Cluj-Napoca, Romania, 2015; pp. 21-27.

7. Ye, X.; Yang, B.; Nie, Y.; Yu, S.; Li, Y. Influence of Nb addition on the oxidation behavior of novel Ni-base superalloy. Corros. Sci. 2021, 185, 109436. [CrossRef]

8. Sun, S.; Li, L.; Hu, K.; Yue, Z.; Yu, Z. Fretting fatigue damage mechanism of Nickel-based single crystal superalloys at high temperature. Int. J. Mech. Sci. 2020, 186, 105894. [CrossRef]

9. Hu, J.; Wang, X.; Zhang, J.; Luo, J.; Shen, Z. A general mechanism of grain growth-I. Theory. J. Mater. 2021, in press.

10. Omori, T.; Kusama, T.; Kawata, S.; Ohnuma, I.; Sutou, Y.; Araki, Y.; Ishida, K.; Kainuma, R. Abnormal grain growth induced by cyclic heat treatment. Science 2013, 341, 615327. [CrossRef] [PubMed]

11. Lee, S.; Yoon, D.; Henry, M. Abnormal grain growth and grain boundary faceting in a model Ni-base superalloy. Acta Mater. 2000, 48, 3071-3080. [CrossRef]

12. Kim, S.; Yong, Y. Grain boundary segregation, solute drag and abnormal grain growth. Acta Mater. 2008, 56, 3739-3753. [CrossRef] 